OPEN ACCESS

Edited by:

Juncai $X u$,

Case Western Reserve University,

United States

Reviewed by:

Wenyuan Ren,

Northwest $A$ and F University, China

Hao Liu,

China University of Geosciences,

China

*Correspondence:

Yuan KeKuo

kkwd1985@163.com

Gao Shan

gaoshan@xijing.edu.cn

Specialty section: This article was submitted to

Structural Materials,

a section of the journal

Frontiers in Materials

Received: 28 July 2020 Accepted: 28 September 2020 Published: 17 November 2020

Citation:

Yuan KK, Gong Y, Fu SJ, XU SH, Liu $K D, Y u H D$ and Gao S (2020)

Development of Quick-Solidifying

Foamed Concrete for Mine Fires

Extinguishment and the Basic

Performances Tests.

Front. Mater. 7:587998.

doi: 10.3389/fmats.2020.587998

\section{Development of Quick-Solidifying Foamed Concrete for Mine Fires Extinguishment and the Basic Performances Tests}

\author{
Yuan KeKuo ${ }^{1,2 *}$, Gong Yu ${ }^{1}$, Fu Shaojun ${ }^{1,2}$, Xu Shuanhai ${ }^{3}$, Liu Kaide ${ }^{1,2}$, Yu Hongdan ${ }^{4}$ and \\ Gao Shan ${ }^{1,2 *}$ \\ ${ }^{1}$ College of Civil Engineering, Xijing University, Xi'an, China, ${ }^{2}$ Shaanxi Key Laboratory of Safety and Durability of Concrete \\ Structures, Xi'an, China, ${ }^{3} X i$ 'an Research Institute of China Coal Technology and Engineering Group, Xi'an, China, ${ }^{4}$ State Key \\ Laboratory of Geomechanics and Geotechnical Engineering, Wuhan, China
}

Coal mine fires have continuously remained the primary disasters in coal mining worldwide. Cement-based inorganic foam concrete, e.g., for engineering filling and coal mine fire extinguishing, has become the first choice for responding to such fires. The objective of this study was to propose quick-solidifying foamed concrete materials based on laboratory tests, and to test the properties of these materials. The stability of a foamed slurry and solidified stone of a quick-solidifying foamed concrete were tested, along with the rheological properties, curability, shrinkage, high-temperature resistance, and cracking of the slurry during solidification. The laws and values of these characteristics were obtained. The results finally show that the quick-solidifying foamed concrete developed in this study has good performance with regard to filling and fire prevention in the large spaces of a mine.

Keywords: quick-solidifying, foamed concrete, solidifying characteristic, rheological property, sealability, high temperature resistance

\section{INTRODUCTION}

Coal mine fires have always represented the main disasters in coal mining worldwide (Pomroy and Carigiet, 1995; Jones et al., 2018). In China, $72.86 \%$ of large- and medium-sized coal mines have a serious or severe risk of natural ignition (Kuenzer et al., 2012; Qi et al., 2013). The frequent occurrences of mine fires, especially from spontaneous combustion, have seriously hindered the smooth progress of safety production. Fortunately, owing to developments in forecasting, mechanization, and even intelligent mining technology (Tian and Zhang, 2019), the threats to the lives of miners have been significantly reduced in recent years.

From summaries of practices and statistical analysis, it has been determined that the spontaneous combustion sources in a mine are mainly distributed in two areas of the goaf, upper and lower corners, coal pillars, roof of the roadway and vicinity of the fault, and roadway rises: most of these are high fire risk zones (Zhou, 2010). The traditional method (of building closed walls under a well) requires workers to work in specific locations under the well, and is difficult to implement in case of a sudden fire. Injecting fire-extinguishing materials into a fire area is a common fire prevention method. Although many research studies have been conducted on mine fire prevention and control technology (Wen, 2003; Deng et al., 2003; Qin et al., 2005, Qin, 2009; Yu et al., 2006; Yu et al., 2010), most of the fire-extinguishing materials commonly used at present have difficulty effectively accumulating, and cannot cover fires in all types of mines. The performance of each technology and material is summarized in Table $\mathbf{1 .}$ 
TABLE 1 | Comparison table of main fire prevention technology and material performance.

\begin{tabular}{|c|c|c|c|c|}
\hline Compared items & Flow range and form & Covering coal & $\begin{array}{l}\text { 3D accumulation in } \\
\text { large spaces }\end{array}$ & Comprehensive effect \\
\hline Water & Line & $\times$ & $\times$ & $\times$ \\
\hline Mud & Narrow plane & $\sqrt{ }$ & $x$ & $x$ \\
\hline Inert gas & 3D space & $\times$ & $\times$ & $\sqrt{ }$ \\
\hline Colloid & $3 \mathrm{D}$ in low altitude & $\sqrt{ }$ (easy to crack) & $\times$ & $\times$ \\
\hline Three-phase foam & 3D in middle altitude & $\sqrt{ }$ (easy to crack) & $\times$ & $\sqrt{ }$ \\
\hline
\end{tabular}

It can be seen that the methods of water injection and mud grouting are too old, and that the fire-extinguishing effect is very poor. Colloidal materials have disadvantages in terms of drying shrinkage and cracking and poor leak-proofing properties; moreover, coal fires can be reactivated. The defects of high water-resistant materials include poor weathering resistance (Feng et al., 2010; Feng and Ding, 2010). Three-phase foamed materials are currently the most convenient and efficient for extinguishing fires, but their shortcomings are evident, such as a long concretion time, poor water retention capacity, and a tendency to easily burst. In addition, all of the materials in the table except for the inert gases need to be accurately transported to the ignition points or areas; such transportation is difficult, and requires high-technology elements. In 2017, owing to a high stand fire near the mining face of a coal mine in Yunnan Province in China, it was considered that a fire space could be filled and sealed quickly with a short flow distance without removing the mining equipment from the mining face. Moreover, the filling material could be removed, and the main mining equipment was still usable after the fire was extinguished. The principal area of the coal mine was sealed and the coal mine fire was extinguished using a closed accumulation body, as shown in Figure $\mathbf{1}$.

In regard to choosing materials to fill and seal large spaces of a mine to prevent coal fires, some common requirements should be considered, as follows: 1) Incombustibility, and no ventilation leakage, 2) High vertical accumulation stability and anti-gravity (i.e., in regard to itself), and 3) Widely sourced and economical raw materials. Therefore, cement-based inorganic foamed concrete has become the first choice for engineering filling and coal mine fire extinguishing. The foam concrete creates a uniform distribution of air bubbles throughout the mass of the concrete. At present, almost all foamed concrete slurries have a common disadvantage; they have higher water bleeding than normalweight concrete. If a traditional foamed concrete is optimized so that its water bleeding and foam collapse rates are low and can be quickly consolidated, then a large underground space can be closed quickly. Therefore, the development of key and supporting technologies for quick-solidifying foamed concrete materials requires further study. And for identification of the slurry accumulation and integrity of the stone body, the frequency energy spectrum with $S$ transform can realize flexible and effective identification of defects in the concrete structure (Xu and Wei, 2019).

For the research of fire extinguishing with foam, citizen firefighting has received relatively more attention. The most significant feature of foam is its high foaming factor, i.e., a small amount of raw material can produce a large volume of

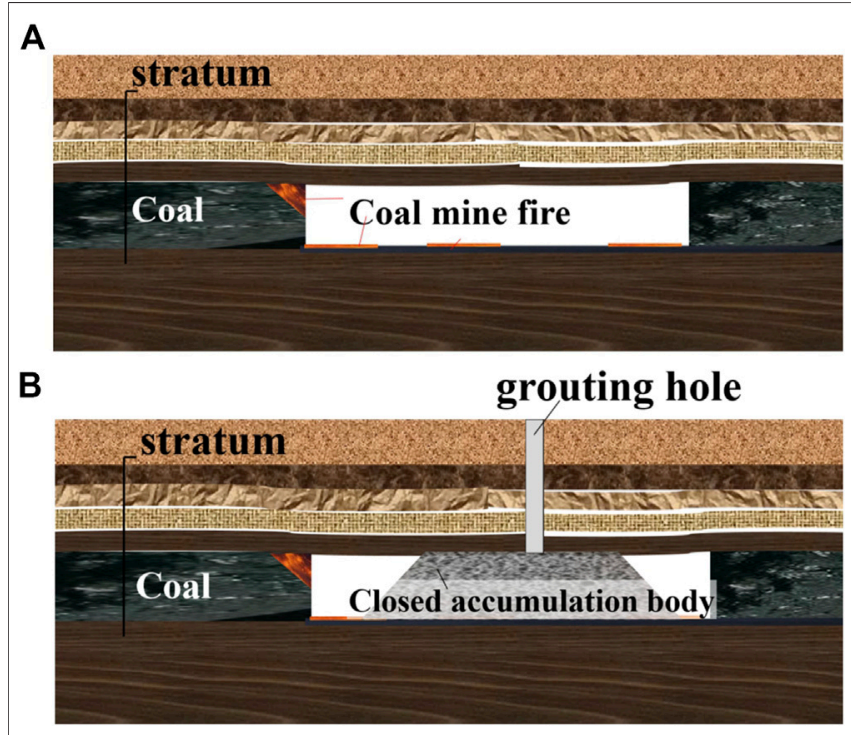

FIGURE 1 | Coal mine fire extinguishment by closed accumulation. (A) Coal mine fire and (B) coal mine sealed by a closed accumulation body.

foamed products, making it easy to cover the target area. There are two general methods for producing foamed concrete: physical methods (including positive pressure bubbling, stirring, and using the negative pressure suction of air) and chemical methods (including chemical and electrochemical). The effects of pressure and gas on foam have also been studied (Aarra et al., 2014). The influences of different anionic surfactants on the properties of foam films have been studied from mixtures of oppositely charged surfactants, and studies have clearly demonstrated that the types and amounts of anionic surfactant can be used to tailor the thickness and stability of foam films (Kristen-Hochrein et al., 2011; Lioumbas et al., 2015).

The aim of the present study is to propose a quick-solidifying foamed concrete material, and to investigate whether the material properties are suitable for achieving high filling and fire prevention in the large space of a mine. The stability,

TABLE 2 | Cement chemical composition.

\begin{tabular}{llllllll}
$\begin{array}{l}\text { Main chemical } \\
\text { composition }\end{array}$ & SiO2 & Al2O3 & TFe2O3 & MgO & CaO & Na2O & K2O \\
\hline Proportion ( \%) & 19.85 & 4.95 & 2.63 & 2.57 & 59.67 & 0.35 & 0.84
\end{tabular}


curability, air permeability, high-temperature resistance, and water resistance of the quick-solidifying foamed concrete are studied in detail, to lay the foundation for application of the material in a mine fire area.

\section{Raw Materials and Basic Physical Characteristics}

Quick-solidifying foamed concrete refers to a multiphase system prepared by adding small amounts of foaming agent, solidifying agent, and other additives to a cement slurry (sometimes by adding an appropriate amount of fly ash). It can flow three-dimensionally, and provides good fire suppression efficiency; it can also be generated in large quantities with relatively small amounts of raw materials. The physical properties of the raw materials used in this experiment are as follows.

\section{1) Cement:}

The cement used was the commercially available Qinling brand PO42.5 cement, with a density of $3.1 \mathrm{t} / \mathrm{m} 3$. The main chemical compositions are listed in Table 2.

The particle size distribution of the cement (as measured with a laser particle size analyzer) is shown in Figure 2A.

2) Fly ash:

The fly ash was taken from the Shaanxi Huxian No. 2 Thermal Power Plant, with a bulk density of $0.92 \mathrm{t} / \mathrm{m} 3$, apparent density of $2.22 \mathrm{t} / \mathrm{m} 3$, and sieve balance of $36.1 \%$ under a $0.045 \mathrm{~mm}$ square hole sieve. The main chemical components are listed in Table 3. The particle size distribution of the fly ash (as measured with a laser particle size analyzer) is shown in Figure 2B.

As shown, the particle size of the fly ash particles used is mainly concentrated between 2 and $100 \mu \mathrm{m}$.

3) Liquid phase:

The water used in this experiment was tap water. In some water-deficient mining areas, waste water pumped into the ground can be used as the liquid phase, thereby saving water resources and reducing costs.

4) Foaming agent:

The so-called foaming agent is the substance that generates the cement slurry pores. Foaming agents can be divided into three categories: chemical foaming agents, physical foaming agents, and surfactants. Chemical foaming agents are compounds that release carbon dioxide and nitrogen gas after thermal decomposition, forming pores in the polymer composition. Physical foaming agents are foam pores that change through the physical form of a substance, i.e., they are formed by the expansion of compressed gas, volatilization of liquid, or dissolution of solids. Foaming agents have high surface activity, and can effectively reduce the surface tension of the liquid. A double electron layer is arranged on the surface of a liquid membrane to surround the air to form bubbles, and then the foam comprises of single bubbles. Conventional blowing agents are used as surfactants.

It is difficult for a single surfactant to suspend fly ash or yellow mud, and various ions and impurities in the slurry can easily cause the foaming agents to lose foaming performance. Generally, a single surfactant is only suitable for two-phase foaming, and it is difficult to suspend solid media. In view of the current research and use of foaming agents, this research does not specifically conduct research and development on foaming agents. Only the main engineering foaming agents on the market are selected for experiments, to screen for a foaming agent with a large foaming factor and stable foam, i.e., a high-efficiency foaming agent providing extended and uniform foaming. The foaming agent must be diluted with water; the relationship between the foaming agent concentration (dilution factor $=\frac{\text { foaming agent weight }}{\text { water weight }}$ ) and foaming capacity is shown in Figure 3.

As shown, the greater the foaming agent concentration, the higher the foaming capacity; however, after the concentration exceeds $10 \%$, the foaming factor increases very slowly with increases in concentration. Thus, the optimal foaming agent concentration is $10-15 \%$.

\section{Development of Quick-Solidifying Foam Concrete}

The development of the quick-solidifying foamed concrete is conducted based on the following preparation steps, and is illustrated in Figure 4.

Dilution of foaming agent: The foaming agent is diluted with water at a ratio of 1:10 to prepare a foaming liquid, and then the
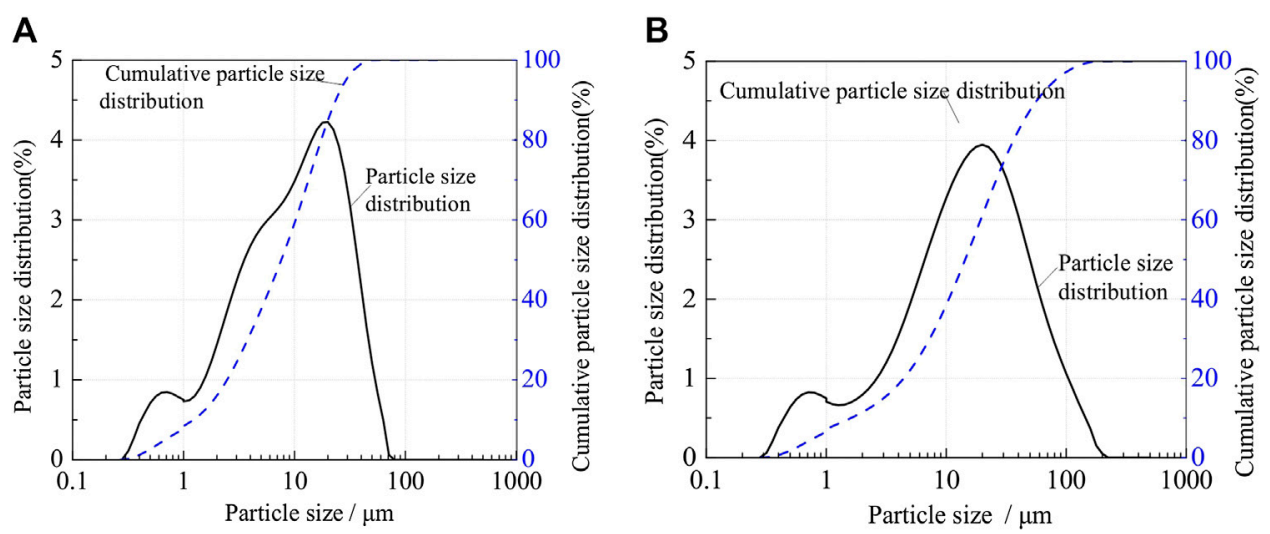

FIGURE 2 | Particle size distribution of (A) Qinling PO42.5 and (B) fly ash. 
TABLE 3 | Chemical composition of fly ash.

\begin{tabular}{lllllllll}
$\begin{array}{l}\text { Main chemical } \\
\text { composition }\end{array}$ & SiO2 & Al2O3 & Fe2O3 & MgO & CaO & Na2O & K2O \\
\hline Proportion (\%) & 53.58 & 25.55 & 5.71 & 1.27 & 6.43 & 0.57 & 1.37
\end{tabular}

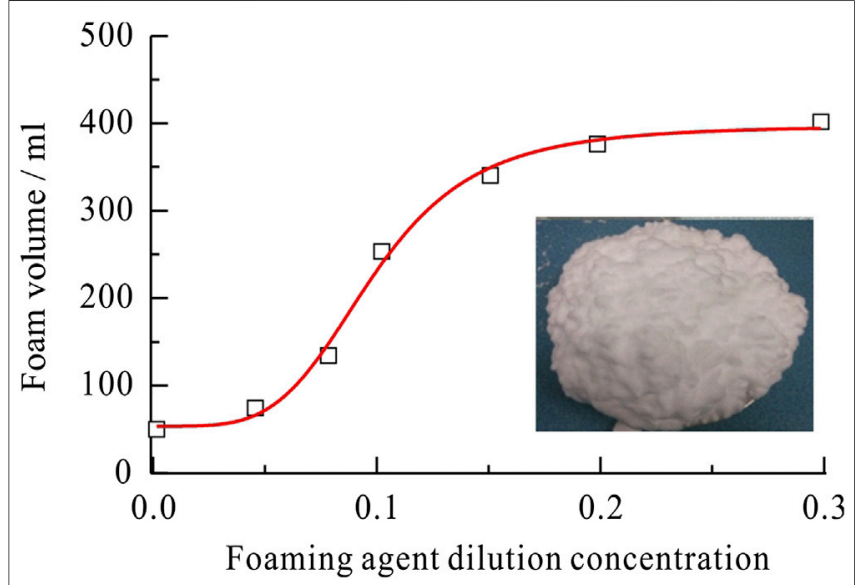

FIGURE 3 | Relationship between foaming agent concentration and foam volume.

foam is made in a foaming machine. The volume of the foam is measured with a measuring cup.

Slurry preparation: A small amount of water (approximately $1 / 20$ of the designed water consumption) is added into the mixer to lubricate the barrel wall. Then, the mixer is activated, and the slurry is added in sequence at a low speed (approximately $30-40 \mathrm{r} / \mathrm{min}$ ). Simultaneously, water is added in proportion until the addition is complete, and stirring continues while waiting for the addition of foam.

Add foam: After the slurry is prepared, the machine continues, and the "twice method" is used to add foam into the stirring state. In particular, a small amount of foam is initially added (approximately $1 / 4$ to $1 / 5$ of the total foam); it is mixed with the gel slurry to make the slurry thinner and more easily dispersed. Then, the remaining foam is added and stirred at high speed for 2-3 min, to obtain a uniformly mixed quicksolidifying foamed concrete slurry.

Foamed concrete preparation: When floating foam cannot be seen on the slurry surface after high-speed stirring, the foamed concrete is prepared and discharged. At this step, the solidifying agent can be added to the foamed cement slurry. Then, the preparation of the quick-solidifying foamed concrete is complete.

According to the above preparation steps, cement is used as the basic material, and the fly ash, foaming agent, and curing agent are used as the auxiliary materials (the amounts of fly ash, curing agent, and water lead to the ratio of the cement quality; the amount of foam affects the volume of the foam and slurry volume ratio). Foamed concrete with different properties can be prepared by varying the added amounts of each component. The main characteristics of the material relate to the stability and fluidity of the slurry and its solidified body, in addition to the curability, shrinkage, sealing, high-temperature resistance, water resistance, and cracking performance in the curing process. Performance tests are conducted, as described below.

\section{MAIN CHARACTERISTICS OF FOAMED SLURRY}

\section{Stability of Foamed Slurry}

As foamed concrete is mainly used for filling and sealing large underground spaces, it must be able to accumulate to a high position without support. Accordingly, it does not require higher strength (but can be solidified quickly); rather, the primary index is the slurry stability. The stability of the foamed concrete slurry denotes how long the foam can exist without breaking. The indicators are the subsidence distance and amount of bleeding, which can be measured using the instrument shown in Figure 5 . According to the scale of the upper container, the subsidence distance (the amount of change of the foam position relative to its position at the initial time in the test) when the foam bursts can be determined. Below the container, a precision electronic balance accepts the foam leakage from the upper part, and measures the amount of water secreted by the ruptured foam.

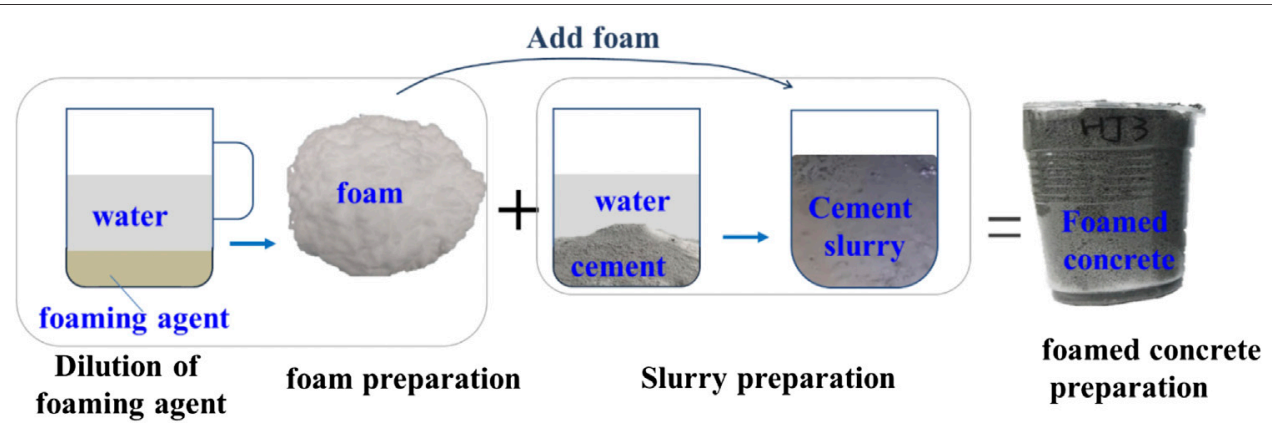

FIGURE 4 | Steps of development of foamed concrete. 


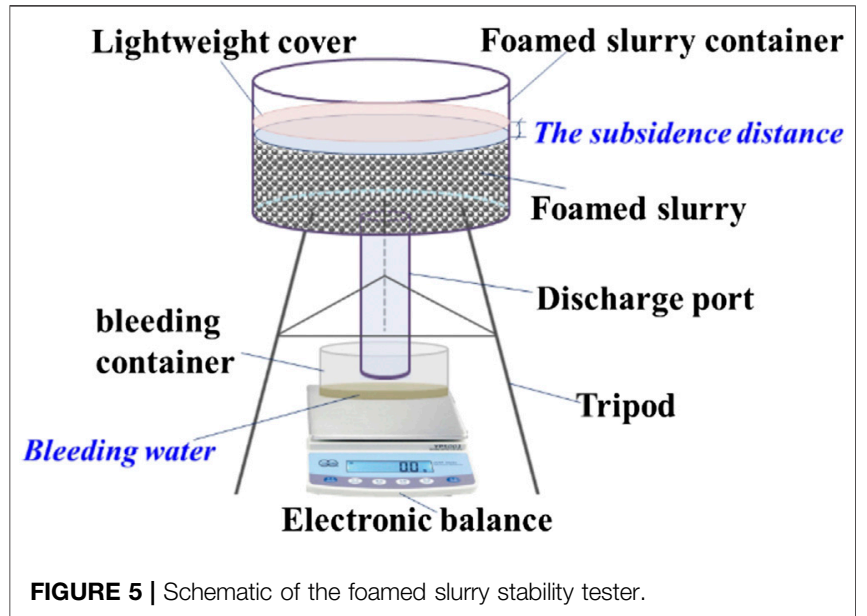

\section{Stability of Conventional Foamed Slurry Without a Curing Agent}

If the stability of a conventional foamed concrete without a curing agent is good, the stability of a quick-solidifying foamed concrete after adding a curing agent should be excellent. Therefore, $200 \mathrm{ml}$ of cement slurry were used to investigate the stability of a conventional foamed concrete slurry under different parameters, e.g., the dilution concentration of the foaming agent, volume of foam added, water-cement ratio, and amounts of different curing agents added.

The stability values of a conventional foamed concrete without a curing agent at different water-cement ratios and different foam volumes (bleeding process and defoaming process) are shown in Figures 6, 7.

As shown, during the preparation of the foamed concrete slurry, the smaller the water-cement ratio of the slurry and the smaller the volume of foam added, the higher the stability of the resulting foamed concrete (i.e., the bleeding volume and subsidence distance are relatively smaller). This is because the greater the concentration of cement slurry, the denser the particles are attached to the foam, the denser and stronger the foam membrane formed is, the more resistant the foam is to external interference, and the more stable the foamed concrete is. Under these experimental conditions, the foamed concrete with a water-cement ratio of 0.5 and three times the amount of foam added provides relatively good stability.

\section{Stability of Quick-Solidifying Foamed Slurry} According to the literature and engineering practice, options for cement solidifying agents include water glass (sodium silicate, liquid) and hemihydrate gypsum (powder). Throughout the test, the side effect of the water glass on the foaming effect was evident; therefore, powdered hemihydrate gypsum was selected as the solidifying agent to prepare the quick-solidifying foamed concrete.

In this experiment, the stability of the quick-solidifying foamed slurry was tested at room temperature $\left(25 \sim 30^{\circ} \mathrm{C}\right)$ when the water-cement ratio was in the range of $0.5-1$, as shown in Figure 8. The quick-solidifying foamed slurry was tested at high temperatures in a steel barrel; the bottom of the barrel was heated by an electric stove.

The test showed that the settlement distance of the quicksolidifying foam concrete was 0 within the experimental range.
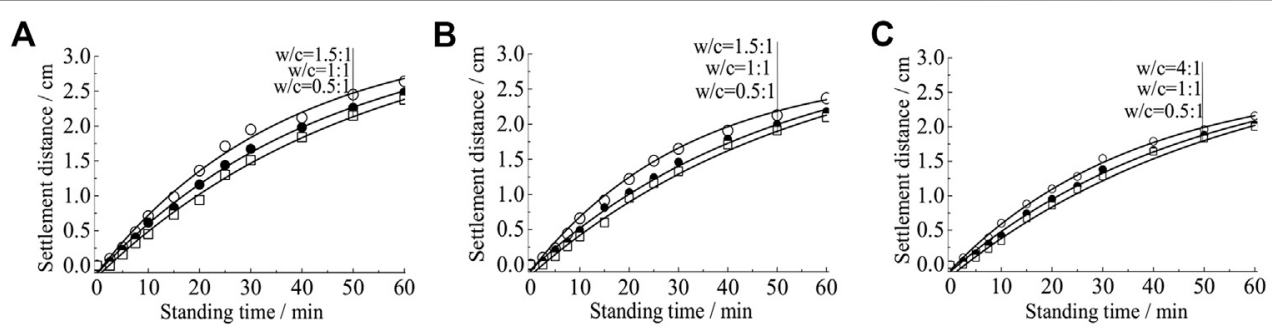

FIGURE 6 | Settlement process of conventional foamed concrete without curing agent under (A) vf/vs $=1.5$, (B) vf/vs $=3$, and (C) vf/vs $=5$. Note: vf, volume of foam; vs, volume of slurry.
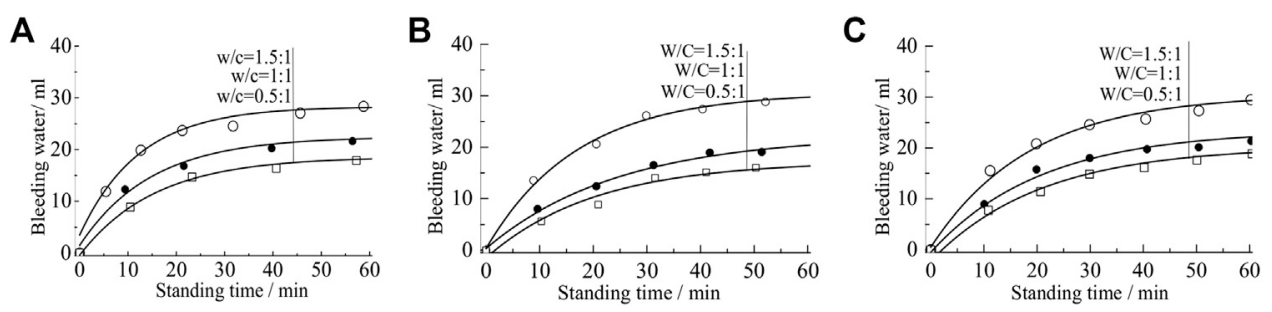

FIGURE 7 |Dewatering speed of conventional foamed concrete without curing agent under (A) vf/vs $=1.5$, (B) vf/vs $=3$, and (C) vf/vs $=5$ Note: vf, volume of foam; vs, volume of slurry. 
A

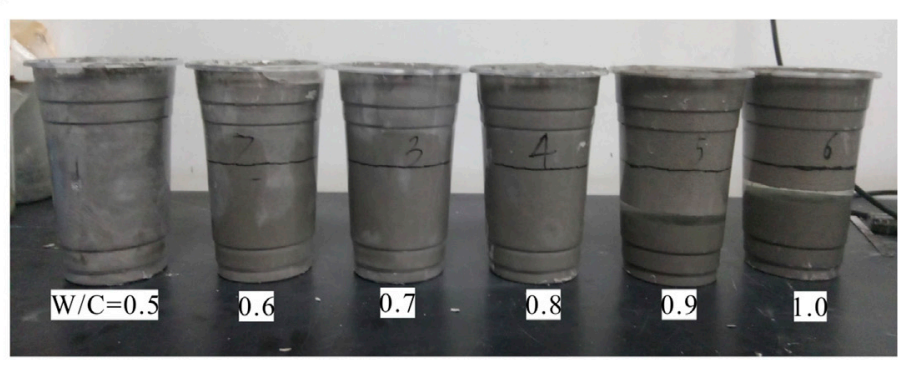

B

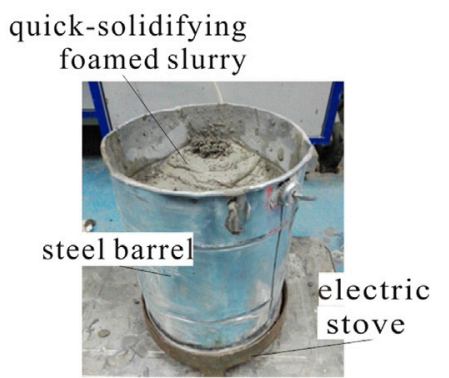

FIGURE 8 | Stability of quick-solidifying foamed slurry. (A) Quick-solidifying foamed concrete at different water-cement ratios at room temperature and (B) quicksolidifying foamed concrete at high temperature.

When the water-solid ratio was greater than 0.8 and the amount of added foam was greater than five times the initial amount, there was significant bleeding (samples No. 5 and No. 6, Figure 8). Overall, the results show that the stability of the quick-solidifying foamed concrete is very good, and that the solidifying process is very quick. The measured solidifying time is discussed in detail in Stability of Quick-Solidifying Foamed Slurry.

\section{Rheological Properties of Quick-Solidifying Foamed Slurry}

Rheology refers to flow and deformation under an external force. For fluids, the rheological properties are usually represented by variable parameters, e.g., the rheological curves, plastic viscosity, dynamic shear force (yield point), static shear force (gel strength), and apparent viscosity. The viscosity is the resistance to flow, and the yield stress is the energy barrier required when flow occurs. The quicksolidifying foamed concrete comprises of a lightweight and low-consumption slurry. The rheological parameters and rheological curve were measured using a Brookfield R/S rheometer. Each test comprised two parallel tests, to avoid errors. Figure 9 shows the shear stress and viscosity curves of the quick-solidifying foamed concrete slurry.

As shown, the shear stress increases slowly with an increase in the shear rate at the different volume ratios of the foam/slurry. The viscosity gradually decreases, and tends toward a stable value (approximately 0.4 Pas). The establishment and numericalization of the rheological model will be provided in another study.

\section{Solidifying Characteristics of Quick-Solidifying Foamed Concrete}

The solidifying properties of the quick-solidifying foamed concrete (solidified stone), including the initial and final solidifying times and density of the solidified body, were tested using an improved Vicat apparatus.

The test results for the solidifying time (initial and final solidifying time) are shown in Figure 10. The effects of the water-cement ratio and amount of foam on the density of quicksolidifying foamed concrete are shown in Figure 11.

It can be seen from the figure that the smaller the watercement ratio and volume of foam and the larger the amount of solidifying agent, the shorter the initial and final solidifying times of the quick-solidifying foamed concrete. The shortest solidifying time is approximately $15 \mathrm{~min}$.

In this experiment, the solidifying agent was added in the range of $20-100 \%$ (relative to the quality of the cement), and the water-cement ratio was in the range of $0.5-1$. Then, throughout
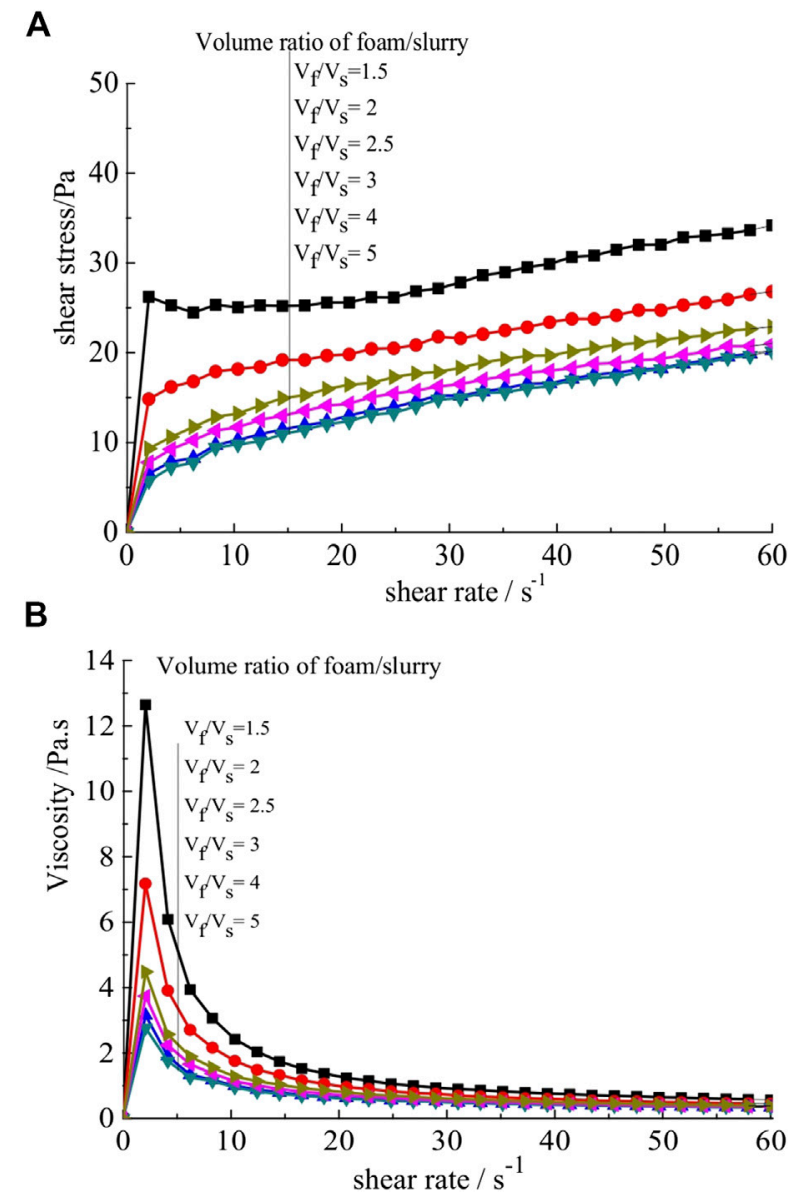

FIGURE 9|Rheological curves. (A) Shear stress, (B) viscosity of quicksolidifying foamed slurry under different foam volume $(\mathrm{W} / \mathrm{C}=0.5)$. 

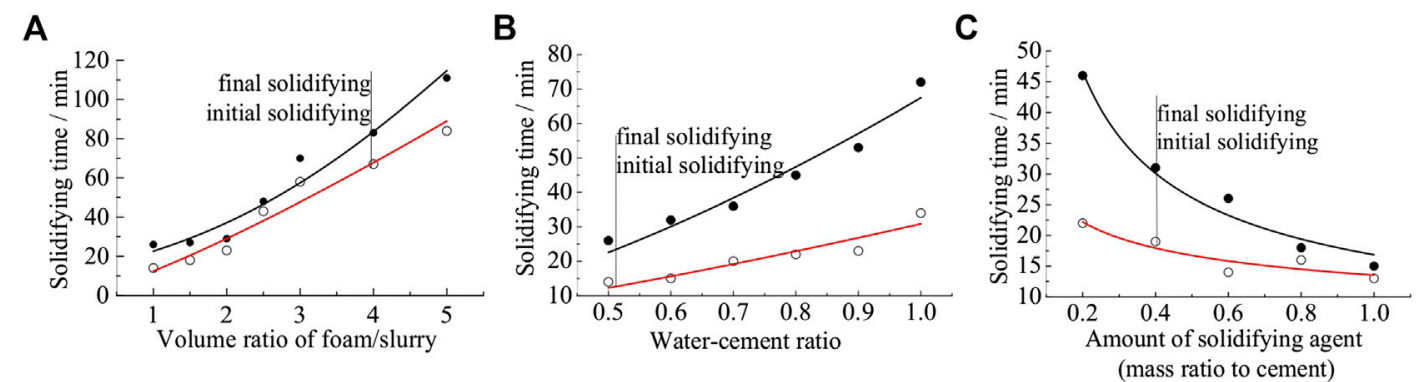

FIGURE 10 | Solidification time of quick-solidifying foamed slurry and foamed concrete with (A) different volumes of foam, (B) different water-cement ratios, and (C) different amounts of curing agent.

all of the tests, the subsidence distance of the test remained 0 , and there was only slight bleeding (the stability of the quicksolidifying foamed concrete was very good and the solidification process was quicker than the bleeding; thus, the

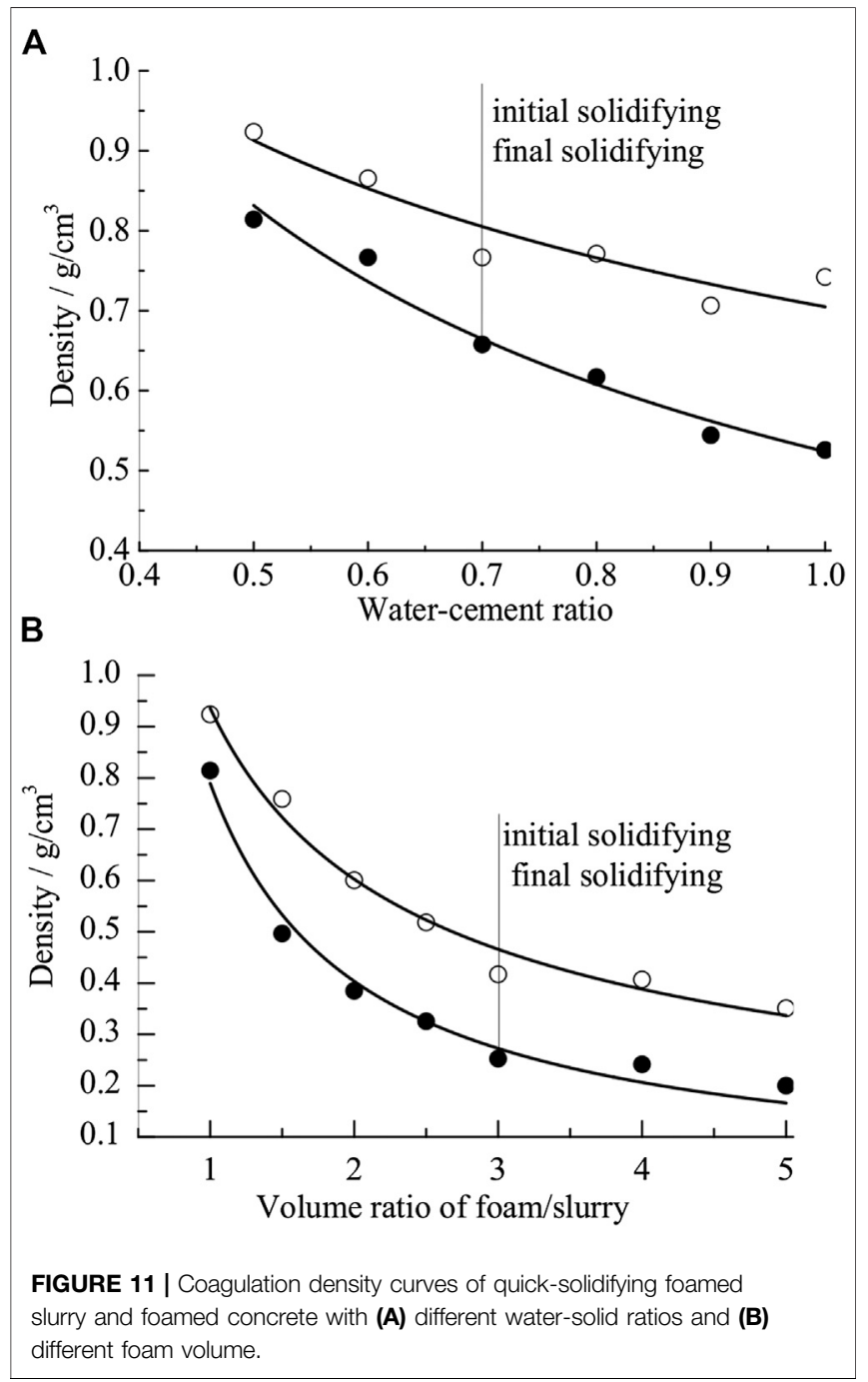

data of the settlement distance and bleeding could not be measured).

\section{High-Temperature Resistance of Quick-Solidifying Foamed Concrete}

Weathering resistance refers to the ability of a material to be desorbed and maintain its original properties under the influence of physical factors such as moisture and temperature changes. In regard to quick-solidifying foamed concrete for extinguishing mine fires, the high temperature resistance refers to the solidifying process of the foamed slurry and the stability of the solidified stone at high temperatures.

In this study, to test the high-temperature resistance of the quick-solidifying foamed concrete slurry, the foamed slurry was placed in a steel barrel, and the bottom of the barrel was heated by an electric stove at a high temperature. Then, the temperatures of the foamed slurry at different depths of the barrel were observed during the heating and solidifying process, until the foamed slurry was completely solidified. A schematic of the test is shown in Figure 12. The depth of the

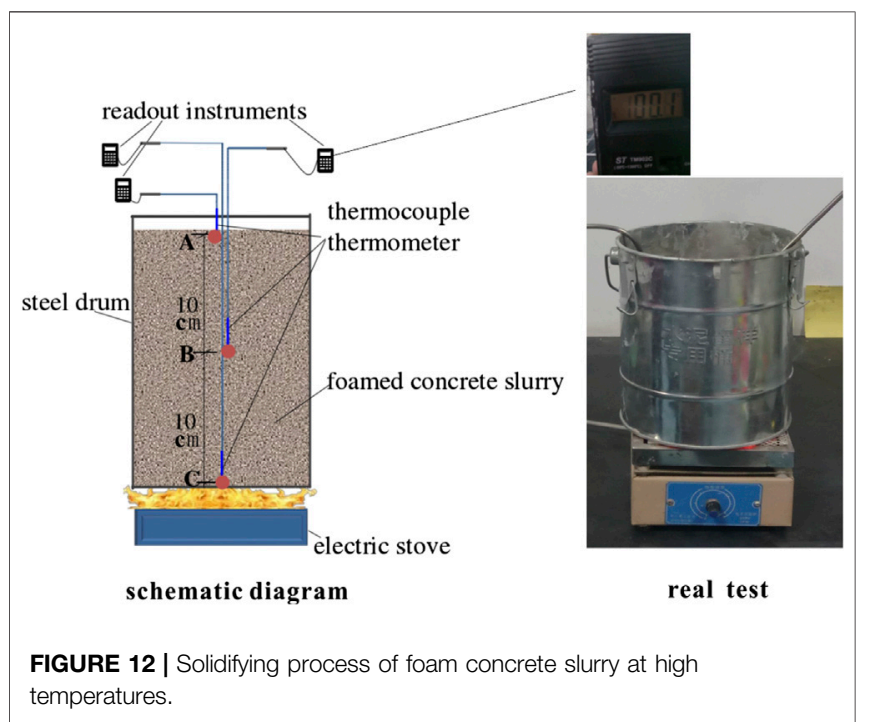



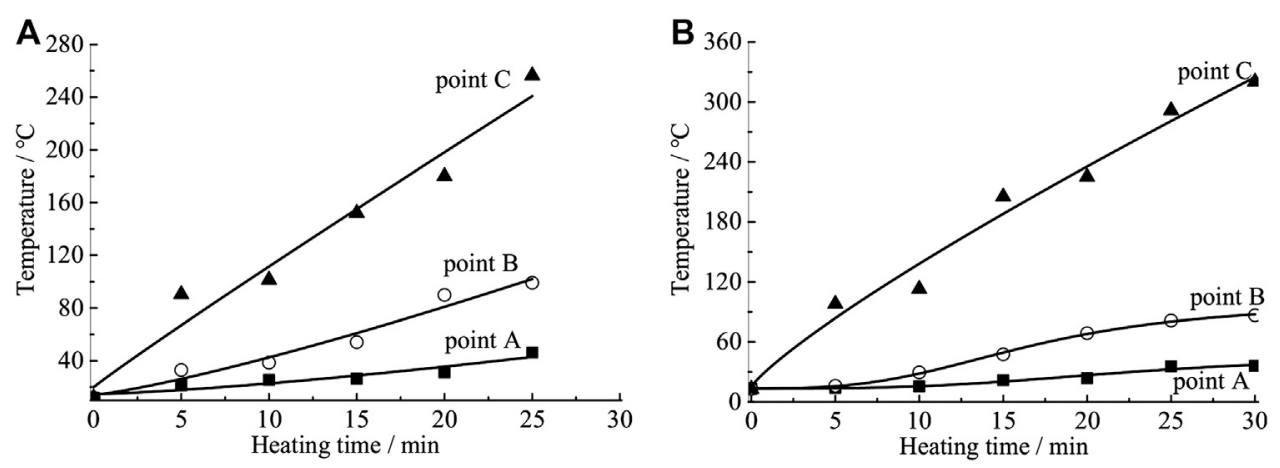

FIGURE 13 | Temperature curves of (A) conventional foamed slurry and (B) quick-solidifying foamed slurry under heating.

foam in the barrel is $20 \mathrm{~cm}$ from the top, the graduation line of slurry top is $0 \mathrm{~cm}$.

The test process and results are shown in Figures 13, 14. Figure 13 shows the solidifying processes of conventional foamed concrete and quick-solidifying foamed concrete (at a volume ratio of foam/slurry $=1$ ), under a volume ratio of foam-to-cementslurry of 1:1 and water-cement ratio of $\mathrm{W} / \mathrm{C}=1: 1$.

The temperature curves show that the solidified foamed concrete has a good thermal insulation performance. When the temperature of the bottom of the barrel is above $300^{\circ} \mathrm{C}$, the foam in the higher part $(0-10 \mathrm{~cm})$ of the barrel is only close to the boiling point of water. In contrast, a conventional foamed concrete without a curing agent boiled after $20 \mathrm{~min}$, and the foam quickly collapsed.

\section{MAIN CHARACTERISTICS OF THE SOLIDIFIED BODY OF QUICK-SOLIDIFYING FOAMED SLURRY High-Temperature Resistance of the Solidified Body}

The solidified stone body of the quick-solidifying foamed concrete slurry was burned by an acetylene gun to observe whether the foamed stone block was scattered during a burning process, as shown in Figure 15.
The burning test showed that when the foam solidified body was burned above $800^{\circ} \mathrm{C}$ for $10 \mathrm{~min}$, there were no combustion or thermal fragmentation phenomena.

\section{Seal-Ability of Solidified Body}

Seal-ability is a core property of coal fire materials, i.e., to ensure that the material does not crack owing to water loss and dry shrinkage. A device (Figure 16) was designed to measure this performance. The principle was to determine the permeability of the material through a certain thickness under different pressure differences within a certain time.

The glass rotameter did not respond under a lower pressure; however, with the increase in air pressure, the glass rotameter reading suddenly increased (at a point called the critical pressure). The critical pressures under different volume ratios of foam/slurry are shown in Figure 17.

The experiments show that it is difficult for air to pass through the sample under a small pressure, further indicating that this material has a good extinguishing and fire prevention performance. It can completely isolate air under the condition of a natural minimum pressure difference; when the volume of foam added is excessive (such as greater than five times the initial amount), the isolation is poor.

\section{RESULTS}

In view of the current situation regarding coal mine fire control in China (and especially the shortcomings in the sealing of large
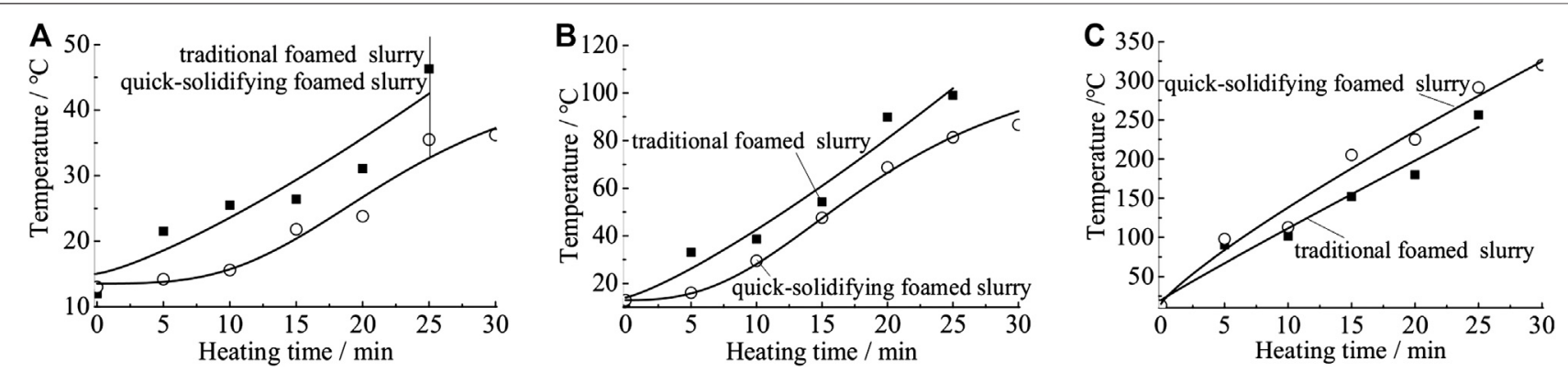

FIGURE 14 | Temperature curves of foamed concrete under heating at (A) point A, (B) point B, and (C) point C of the steel drum. 


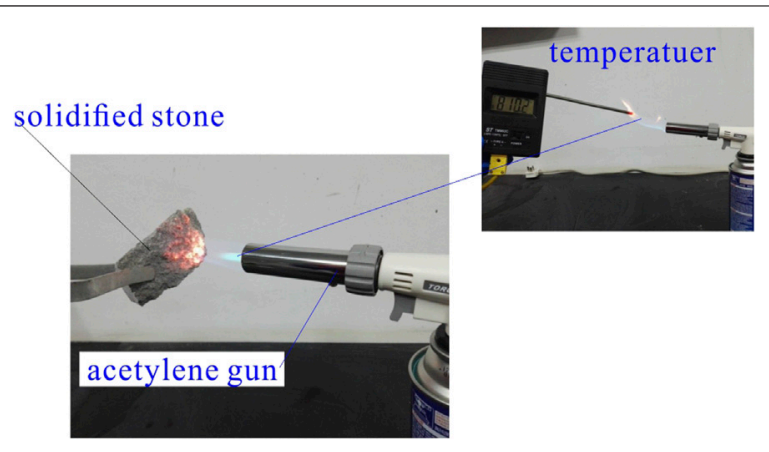

FIGURE 15 | High-temperature resistance test of solidified body of quick-solidifying foamed concrete.

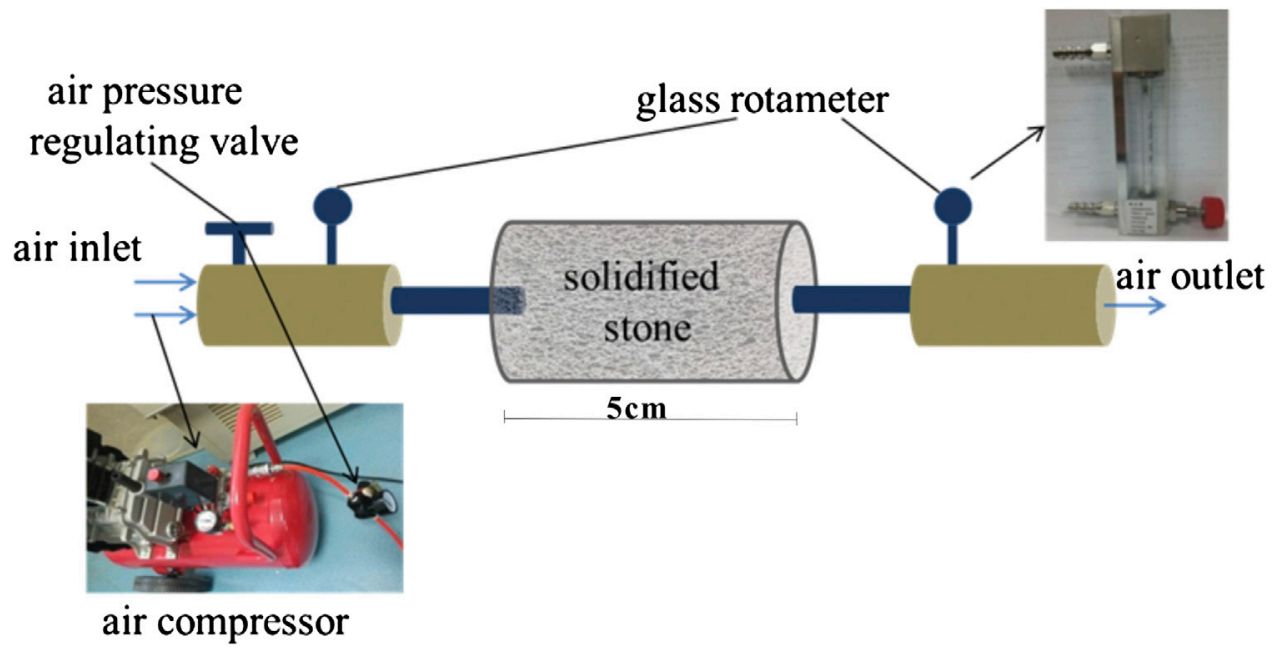

FIGURE 16 | Diagram of device for measuring the seal-ability of solidified stone.

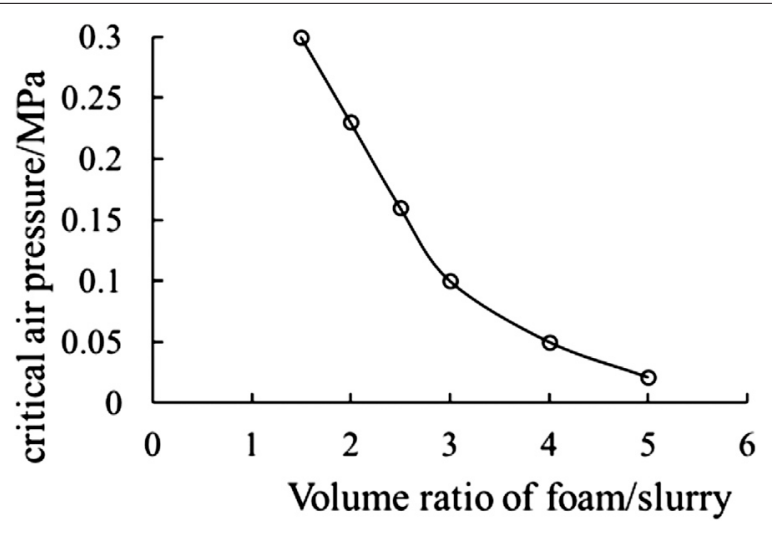

FIGURE 17 | Critical pressures under different volume ratios of foam/slurry. 
spaces), a new type of foamed concrete was prepared for filling large spaces in coal mines, providing quick solidification, light weight, low bleeding, and little to no risk of collapse in the solidified stone. Then, the stability, rheology, solidifying characteristics, high-temperature resistance, and seal-ability of the quick-solidifying foamed concrete were tested. The main conclusions are as follows.

1) The optimization dosages of the quick-solidifying foamed concrete are as follows: a foaming agent concentration of $10-15 \%$, water-cement ratio in the range of $0.5-1$, and volume ratio of foam to slurry of less than 5 ( 2 is the best). Under the obtained optimization dosage, the density of the foam concrete material is approximately $380 \mathrm{~kg} / \mathrm{m} 3$.

2) For the foamed concrete slurry, the smaller the watercement ratio of the slurry and the smaller the volume ratio of foam to slurry, the higher the stability (bleeding and settlement distance) of the foamed concrete. The settlement distance of the quicksolidifying foam slurry was 0 when the water-solid ratio was greater than 0.8 and the amount of foam added was greater than five times, and the water bleeding was significant. This indicates that the stability of the quick-solidifying foamed concrete is very good, and that the solidification process is very quick.

3) The shear stress of the foamed concrete slurry increases slowly with an increasing shear rate at different volume ratios of foam/slurry. The viscosity gradually decreases, and tends toward a stable value (approximately 0.4 Pas).

4) Regarding the seal-ability of the quick-solidifying foamed concrete, it is difficult for air to pass through the sample under a small pressure $(<0.1 \mathrm{MPa})$, which shows that this new type of foamed concrete has good extinguishing and fire prevention performance. It can completely isolate air under a natural minimum pressure difference.

5) The high-temperature resistance of the quick-solidifying foamed concrete slurry was tested at different depths in a steel barrel that was heated by an electric stove, and the temperature

\section{REFERENCES}

Aarra, M. G., Skauge, A., Solbakken, J., and Ormehaug, P. A. (2014). Properties of $\mathrm{N}_{2}$ - and $\mathrm{CO}_{2}$-foams as a function of pressure. J. Petrol. Sci. Eng. 116 (4), 72-80. doi:10.1016/j.petrol.2014.02.017

Deng, J., Xu, J., and Chen, X. (2003). Research progress on coal spontaneous combustion mechanism and prediction theory[J]. J. Liaoning Tech. Univ. 22 (4), 455-459. doi:10.3969/j.issn.1008-0562.2003.04.009

Feng, G., and Ding, Y. (2010). Research and application of ultra-high water material filling and mining technology[M]. Xuzhou, China: China University of Mining and Technology Press.

Feng, G., Sun, C., Wang, C., et al. (2010). Research on filling method of goaf with ultra-high water material[J]. J. China Coal Soc. 27 (4), 453-457. doi:10.1016/ S1876-3804(11)60004-9

Jones, R., Lee, S., Maybery, D., and McFarlane, A. (2018). Experiences of a prolonged coal-mine fire. Disaster Prev. and Manag. 27 (5), 534-545. doi:10.1108/dpm-05-2018-0145

Kristen-Hochrein, N., Schelero, N., and von Klitzing, R. (2011). Effects of oppositely charged surfactants on the stability of foam films. Colloids Surf. A Physicochem. Eng. Asp. 382 (1), 165-173. doi:10.1016/j.colsurfa.2010.12. 019

Kuenzer, C., Zhang, J. Z., Sun, Y. L., Jia, Y., and Dech, S. (2012). Coal fires revisited: the Wuda coal field in the aftermath of extensive coal fire research and was observed during the heating and solidifying process until the foamed slurry was completely solidified. The results showed that when the temperature of the bottom of the barrel was above $300^{\circ} \mathrm{C}$, the foam in the higher part $(0-10 \mathrm{~cm})$ of the barrel was only close to the boiling point of water $\left(100^{\circ} \mathrm{C}\right)$.

6) The solidified stone was burned by an acetylene gun to observe whether the foamed stone block was scattered during the burning process. The burning tests showed that when the foam solidified body was burned above $800^{\circ} \mathrm{C}$ for $10 \mathrm{~min}$, there were no combustion or thermal fragmentation phenomena.

\section{DATA AVAILABILITY STATEMENT}

The original contributions presented in the study are included in the article/supplementary materials, further inquiries can be directed to the corresponding author/s.

\section{AUTHOR CONTRIBUTIONS}

GY and LKD conducted the experiments, data analyses, and characterizations. YKK and YHD drafted the manuscript. FSJ and $\mathrm{XSH}$ helped with manuscript preparation and supervised the overall research. YKK and GS finalized the manuscript.

\section{FUNDING}

The project was supported by the Shaanxi Provincial Research Foundation for Basic Research, China (Grant No. 2020JM-642) and the Open Research Fund of State Key Laboratory of Geomechanics and Geotechnical Engineering, Institute of Rock and Soil Mechanics, Chinese Academy of Sciences, Grant NO. Z019021.

accelerating extinguishing activities. Int. J. Coal Geol. 102, 75-86. doi:10. 1016/j.coal.2012.07.006

Lioumbas, J. S., Georgiou, E., Kostoglou, M., and Karapantsios, T. D. (2015). Foam free drainage and bubbles size for surfactant concentrations below the CMC. Colloids Surf. A Physicochem. Eng. Asp. 487, 92-103. doi:10.1016/j.colsurfa. 2015.09.050

Pomroy, W. H., and Carigiet, A. M. (1995). Analysis of underground coal mine fire incidents in the United States from 1978 through 1992. Washington, D.C.: United States Department of the Interior, Bureau of Mines.

Qi, X., Wang, D., Xin, H., and Zhong, X. (2013). Environmental hazards of coal fire and their prevention in China. Environ. Eng. Manag. J. 12 (10), 1915-1919. doi:10.30638/eemj.2013.238

Qin, B. (2009). Three-phase foam theory and technology to prevent coal spontaneous combustion $[M]$. Xuzhou, China: China University of Mining and Technology Press.

Qin, B., Wang, D., Chen, J., et al. (2005). Experimental research on high-performance fire-fighting three-phase foam. J. China Univ. Min. Technol. 34 (1), 11-15. doi:10. 3321/j.issn:1000-1964.2005.01.003

Tian, S., and Zhang, C. (2019). "A mine fire evaluation system based on vulnerability," in Proceedings of the 11th international mine ventilation congress. Editors X. Chang (Singapore: Springer), 686-694.

Wen, H. (2003). Experimental and numerical simulation research on coal spontaneous combustion process. PhD Dissertation. Xi'an, China:Xi'an University of Science and Technology. 
$\mathrm{Xu}$ J., and Wei, H. (2019). Ultrasonic testing analysis of concrete structure based on S transform. Shock. Vib. 2019, 2693141. doi:10.1155/2019/2693141

Yu, M., Li, Z., Li, D., et al. (2006). Study on evaluation method for fire extinguishing efficacy of additive-containing water mist. China Saf. Sci. J. 16 (2), 85-89. doi:10.16265/j.cnki.issn1003-3033.2006.02.017

Yu, S., Yu, M., Xie, F., et al. (2010). Preventing and controlling spontaneous combustion of top coal in high-collapse area with inorganic foam cementitious materials[J]. J. China Univ. Min. Technol. 39 (2), 173-177. doi:CNKI:SUN:ZGKD.0.2010-02-006

Zhou, F. Z. (2010). Research and Application of coal mine spontaneous combustion Source Location Technology. PhD dissertation. Beijing, China: China University of Mining and Technology.
Conflict of Interest: The authors declare that the research was conducted in the absence of any commercial or financial relationships that could be construed as a potential conflict of interest.

Copyright $\odot 2020$ Yuan, Gong, Fu, Xu, Liu, Yu and Gao. This is an open-access article distributed under the terms of the Creative Commons Attribution License (CC $B Y$ ). The use, distribution or reproduction in other forums is permitted, provided the original author(s) and the copyright owner(s) are credited and that the original publication in this journal is cited, in accordance with accepted academic practice. No use, distribution or reproduction is permitted which does not comply with these terms. 